TITLE:

\title{
Effects of pulsed potential on address electrode in a surface- discharge alternating-current plasma display panel
}

AUTHOR(S):

Ahn, JC; Shintani, Y; Tachibana, K; Sakai, T; Kosugi, $\mathrm{N}$

\section{CITATION:}

Ahn, JC ... [et al]. Effects of pulsed potential on address electrode in a surface-discharge alternating-current plasma display panel. APPLIED PHYSICS LETTERS 2003, 82(22): 38443846

ISSUE DATE:

2003-06-02

URL:

http://hdl.handle.net/2433/50085

\section{RIGHT:}

Copyright 2003 American Institute of Physics. This article may be downloaded for personal use only. Any other use requires prior permission of the author and the American Institute of Physics. 


\title{
Effects of pulsed potential on address electrode in a surface-discharge alternating-current plasma display panel
}

\author{
Jeong Chull Ahn, ${ }^{\text {a) }}$ Youichi Shintani, Kunihide Tachibana, ${ }^{\text {b) }}$ Tetsuo Sakai, ${ }^{c)}$ \\ and Naoki Kosugid) \\ Department of Electronic Science and Engineering, Kyoto University, Kyoto 606-8501, Japan
}

(Received 3 January 2003; accepted 2 April 2003)

\begin{abstract}
The influence of pulsed potential application onto the address electrode of an ac-type plasma display panel was investigated from the observation of front and side views of $\mathrm{Xe}$ atom densities in the metastable $\left(1 s_{5}\right)$ and excited $(2 p)$ states in a unit discharge cell by using microscopic laser absorption spectroscopy and optical emission spectroscopy. It was seen that a predischarge occurs between the address electrode and one of the sustain electrode worked as a preceding anode, which is a similar effect found previously by applying a higher sustain voltage. The predischarge partially erases the surface charge accumulated in the preceding pulse, but it induces a faster main sustain discharge, bowing towards the address electrode, and enhances the production efficiency of $\mathrm{Xe}\left(1 s_{5}\right)$ atoms, if the applied potential is within an optimal range. (C) 2003 American Institute of Physics.
\end{abstract} [DOI: $10.1063 / 1.1580638]$

One of the most important issues of the present alternating-current plasma display panels (ac-PDPs) is to improve luminous efficiency, which is dependent on the composition of rare gases, total pressure, cell structure, and driving wave forms. Various driving techniques using address pulses in sustain periods have been suggested to improve the luminous efficiency. ${ }^{1-5}$ However, real phenomena occurring in the discharge by applying address pulses have not been experimentally investigated as yet. In this work, we examine the behavior of metastable Xe atoms in the $1 s_{5}$ state, $\mathrm{Xe} *\left(1 s_{5}\right)$, under this condition by using the microscopic laser absorption spectroscopy (LAS) technique, which we have developed previously. ${ }^{6-9}$ The near-infrared emission from excited $\mathrm{Xe}$ atoms in the $2 p$ state, $\mathrm{Xe}^{*}(2 p)$, is also examined, which is composed mostly of the 823- and 828-nm lines and correlates with the vacuum ultraviolet emission at 173 and $147 \mathrm{~nm}$ through the cascade transitions to the metastable $\left(1 s_{5}\right)$ and resonance $\left(1 s_{4}\right)$ states. ${ }^{10,11}$ As the total gas pressure or the Xe concentration increases, the emission intensity at $173 \mathrm{~nm}$ from $\mathrm{Xe}_{2}^{*}$ excimers increases through the enhanced production efficiency via three-body collisions of $\mathrm{Xe}^{*}\left(1 s_{5}\right)$ atoms with $\mathrm{Ne}$ and $\mathrm{Xe}$ atoms in the ground states. ${ }^{12,13}$ It is, therefore, of great importance to investigate the total number of $\mathrm{Xe}^{*}\left(1 s_{5}\right)$ atoms for the estimation of the luminous efficiency in ac-PDPs.

The structure of an ac-PDP unit cell shown in Fig. 1(a) was specially designed for the three dimensional (3D) observation of spatiotemporal behaviors. ${ }^{8,9}$ The sustain electrodes of $200 \mu \mathrm{m}$ width made of indium tin oxide (ITO) film were successively covered with a dielectric layer and a $\mathrm{MgO}$ pro-

\footnotetext{
${ }^{a)}$ Venture Business Laboratory, Kyoto University, Yoshida-honmachi Sakyoku, Kyoto 606-8501, Japan.

b) Author to whom correspondence should be addressed; tatibana @ kuee.kyoto-u.ac.jp

${ }^{c)}$ Display Research Laboratories, Co. Ltd., 2-6-12 Tamagawadai Setagayaku, Tokyo 158-0096, Japan.

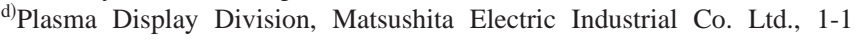
Saiwai-cho, Takatsuki, Osaka 560-1194, Japan.
}

tective layer, and set in parallel to each other on the front glass plate with a gap of $75 \mu \mathrm{m}$. By using transparent glass prisms of $150-\mu \mathrm{m}$ thickness as barrier ribs, we could observe the front and side views of the discharge at the same time. On the rear glass plate, the address electrode also made of ITO was located perpendicularly to the sustain electrodes. A mixture of $\mathrm{Ne}$ and $\mathrm{Xe}(5 \%)$ was filled at a pressure of 500 Torr. The width, frequency, and voltage of the sustain voltage pulses $\left(V_{x}\right.$ and $V_{y}$ ) employed in this experiment were $9.2 \mu \mathrm{s}$, $50 \mathrm{kHz}$, and $200 \mathrm{~V}$, respectively. The width of the address voltage pulses $\left(V_{a}\right)$ was fixed at $800 \mathrm{~ns}$. The timing of $V_{a}$ at the center was adjusted to the rising edge of $V_{x}$, as shown in Fig. 1(b). Hereafter, the time origin $(t=0)$ is defined at the rising edge of $V_{x}$. The values of $V_{a}$ was varied from 0 to 90 $\mathrm{V}$. The LAS measurement of the $\mathrm{Xe}^{*}\left(1 s_{5}\right)$ atom density was performed by tuning the laser wavelength to the $823.1 \mathrm{~nm}$ $\left(2 p_{6}-1 s_{5}\right)$ transition. The IR emission from $\mathrm{Xe}^{*}(2 p)$ atoms

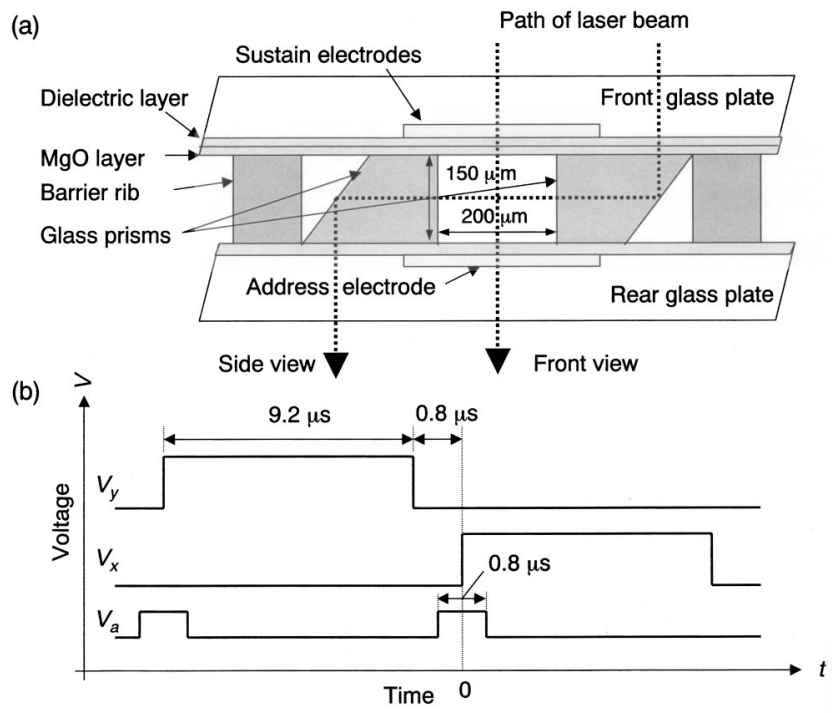

FIG. 1. (a) Structure of the 3D observation cell and (b) wave forms of sustain voltage pulses $\left(V_{x}\right.$ and $\left.V_{y}\right)$ and address voltage pulses $\left(V_{a}\right)$. 


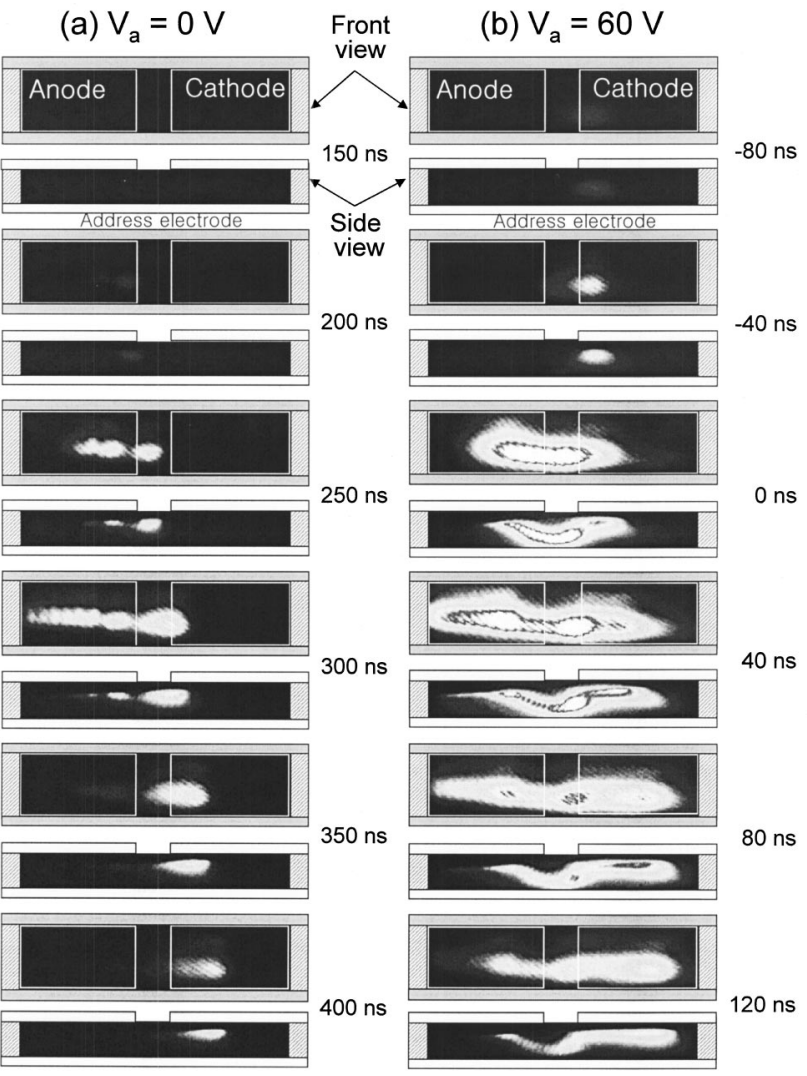

FIG. 2. Temporal sequences of IR emission images measured at address pulse voltages of (a) $V_{a}=0 \mathrm{~V}$ and (b) $V_{a}=60 \mathrm{~V}$ viewed from front (upper frame) and side (lower frame).

was observed by an intensified CCD camera at a gate width of $10 \mathrm{~ns}$. The CCD camera was equipped with a band-pass filter centered at $820 \mathrm{~nm}$ with a full width at half maximum of $20 \mathrm{~nm}$ to observe mostly the $823 \mathrm{~nm}\left(2 p_{6}-1 s_{5}\right)$ and 828 $\mathrm{nm}\left(2 p_{5}-1 s_{4}\right)$ lines. ${ }^{9}$

Figures 2(a) and 2(b) show the images of IR emission from $\mathrm{Xe}^{*}(2 p)$ atoms observed by the CCD camera from $t$ $=150$ to $400 \mathrm{~ns}$ and $t=-80$ to $120 \mathrm{~ns}$ at (a) $V_{a}=0 \mathrm{~V}$ and (b) $V_{a}=60 \mathrm{~V}$, respectively. It is noted that the cathode and the anode in these figures are right and left sides, respectively, with respect to the central gap. Front and side views of the discharge image are shown on the upper and lower parts of each frame, respectively. It is seen that the discharge starts faster as the address voltage is applied. The discharge spreads to each end of sustain electrodes but the appearance is different on each side. The emission intensity above cathode is stronger and it expands outward according to the ion mobility, while it becomes weaker and shrinks inward due to charge accumulation on the electrode surface. ${ }^{14,15}$ The occurrence of a predischarge between the previous anode and the address electrode is clearly seen at $V_{a}=60 \mathrm{~V}$. The predischarge may partially erase the surface charge accumulated on the previous anode, but it induces the main discharge between the sustain electrodes as soon as the next anode pulse is applied. In this discharge mode, the main discharge tends to take a path bowed towards the address electrode. This is apparently quite similar to the case which we observed previously by applying a higher sustain voltage of $250 \mathrm{~V}$, where the charge accumulated on the address electrode due to the Downloaded 04 Mar 2008 to 130.54.110.22. Redistribution subject

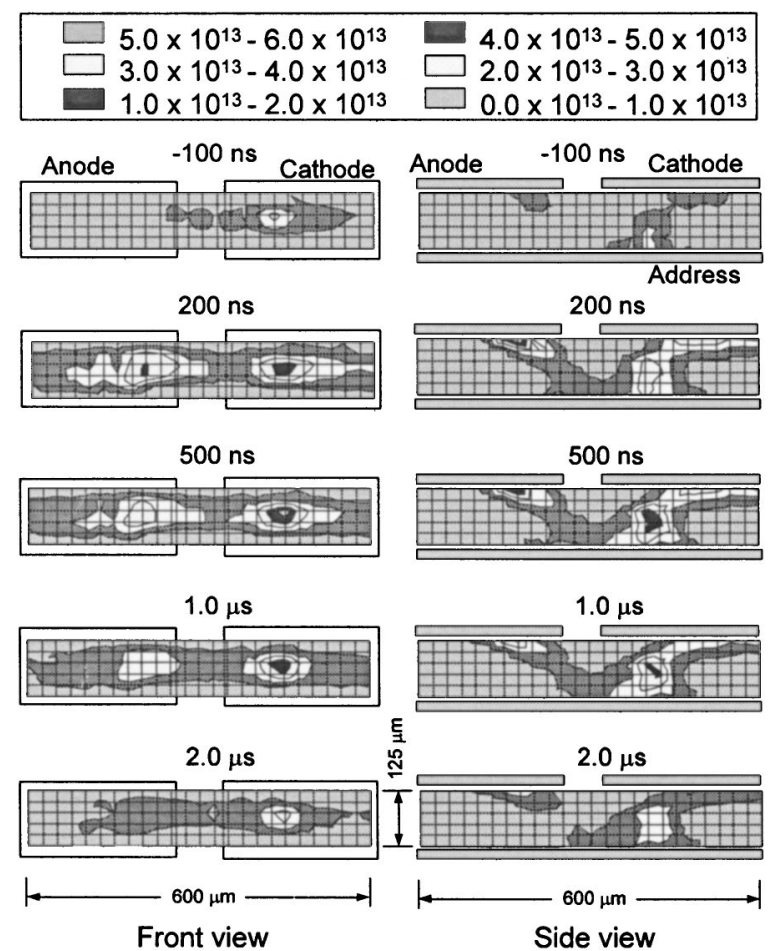

FIG. 3. Temporal sequence of contour diagram of $\mathrm{Xe}^{*}\left(1 s_{5}\right)$ atom density (in units of $\mathrm{cm}^{-3}$ ) at an address pulse voltage of $V_{a}=60 \mathrm{~V}$ viewed from front (left column) and side (right column).

stronger discharge causes a similar predischarge after the falling edge of the preceding sustain pulse. ${ }^{9}$

Figure 3 shows the measured spatiotemporal behaviors of the $\mathrm{Xe}^{*}\left(1 s_{5}\right)$ atom density at the address voltage of $V_{a}$ $=60 \mathrm{~V}$. The graphs on the left side are the distribution of $\mathrm{Xe}^{*}\left(1 s_{5}\right)$ atoms in the front view. In each graph, the leftside electrode is working as anode. In a usual operation mode without the application of $V_{a}, \mathrm{Xe}^{*}\left(1 s_{5}\right)$ atoms begin to be observed at the anode side of the gap and a striated pattern is formed. ${ }^{7-9}$ In this case, however, the excited Xe atoms appear first at the cathode side. From the side view, it is found that the predischarge occurs between address electrode and the previous anode (therefore, the succeeding cathode) at $t<0$, where the address electrode works as the anode, and stimulates the main discharge between the new anode and cathode at $t>0$. The maximum density of $\mathrm{Xe}^{*}\left(1 s_{5}\right)$ atoms reaches $5.5 \times 10^{13} \mathrm{~cm}^{-3}$ on the cathode side.

The discharge current at the sustain electrode $I_{x}$ and address electrode $I_{a}$ were measured by a differential prove through a small resistor of $680 \Omega$. Figures 4(a) and 4(b) show the current wave forms of $I_{x}$ and $I_{a}$, respectively, which were measured at $V_{a}=0,30,60$, and $90 \mathrm{~V}$. Here, we define the response (or delay) time $\tau$ as the time difference between the rising edge of the sustain pulse $(t=0)$ and the peak of the sustain current. At a given sustain voltage of 200 $\mathrm{V}, \tau$ was measured to be $360,135,100$, and $95 \mathrm{~ns}$ at $V_{a}$ $=0,30,60$, and $90 \mathrm{~V}$, respectively, showing a tendency of shortening with the increase of $V_{a}$. The occurrence of predischarge is also seen in the wave forms of $I_{a}$ at $V_{a}=60$ and $90 \mathrm{~V}$, where the address electrode is working as the anode. However, it is noticed that in each wave form of $I_{a}$, a smaller negative peak follows the positive peak just after the start of the main sustain current. It suggests that the address AIP license or copyright; see http://apl.aip.org/apl/copyright.jsp 


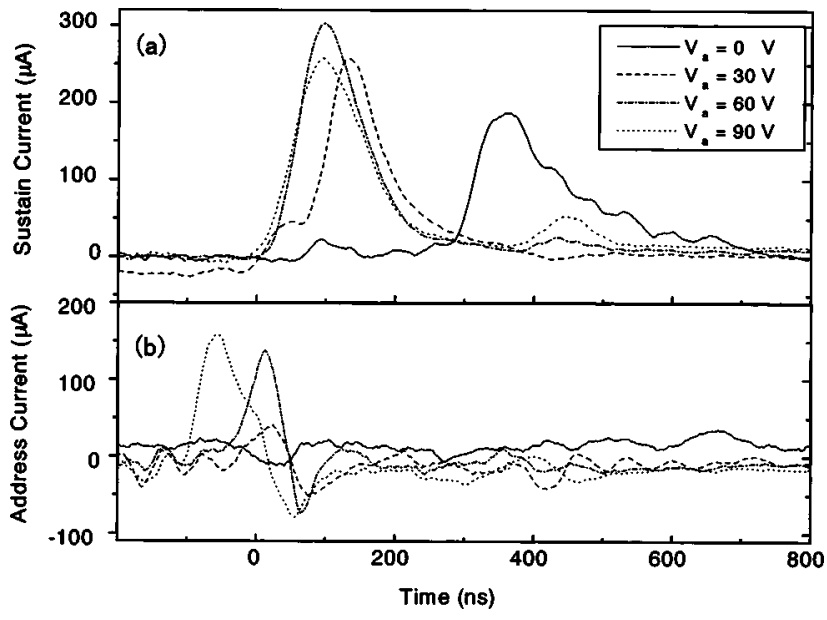

FIG. 4. Wave forms of (a) sustain electrode current $I_{x}$ and (b) address electrode current $I_{a}$ measured at address voltages of $V_{a}=0,30,60$, and $90 \mathrm{~V}$.

electrode turns the role from anode to cathode in the period of sustaining discharge, since the surface of the address electrode has been charged negatively within the predischarge period. Therefore, the polarity of the address electrode charge changes to positive after the sustain period, which is favorable for the next predischarge phase.

Figure 5 shows the total number of $\mathrm{Xe}^{*}\left(1 s_{5}\right)$ atoms, which is spatially integrated in the whole cell volume, as a function of time. The peak number of $\mathrm{Xe}^{*}\left(1 s_{5}\right)$ atoms increases from $1.3 \times 10^{8}$ to $2.1 \times 10^{8}$ as $V_{a}$ increases from 0 to

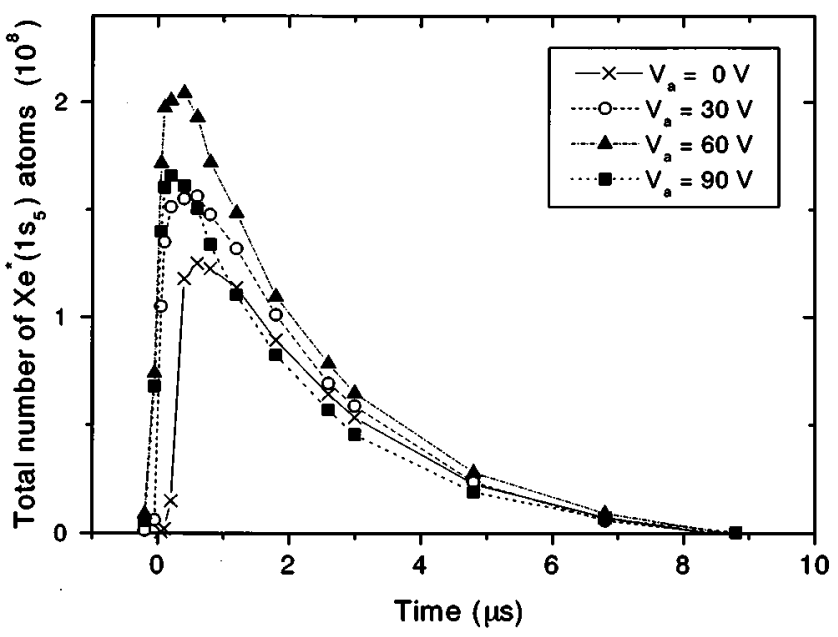

FIG. 5. Temporal behavior of total number of Xe* $\left(1 s_{5}\right)$ atoms in the whole unit cell volume measured at address voltages of $V_{a}=0,30,60$, and $90 \mathrm{~V}$.
$60 \mathrm{~V}$, but it decreases as $V_{a}$ increases further to $90 \mathrm{~V}$. At $V_{a}=90 \mathrm{~V}$, it is suggested that too much surface charge is lost from the sustain electrode in the predischarge, and as the result the main discharge is weakened. At the optimal condition with $V_{a}=60 \mathrm{~V}$, the total input power estimated from the current wave form and the applied voltage increases by about $30 \%$ as compared to the case without $V_{a}$. However, the density of $\mathrm{Xe}^{*}\left(1 s_{5}\right)$ atoms increases by about $70 \%$ and, then, the production efficiency increases by about $25 \%$ with the power expense at the address electrode of only $6 \%$ of the sustain discharge power consumption.

In conclusion, by the application of address pulse potential with a moderate amplitude, say $60 \mathrm{~V}$ in our case, the spatiotemporal distribution of the electric field caused by both the surface charges and the external applied voltages becomes optimal across the whole electrode area, leading to an expanded discharge scheme with higher luminance and luminous efficiency. At higher values of $V_{a}$, however, the predischarge becomes too strong to disturb the optimum balance of the electric field.

This work has been partially supported by Venture Business Laboratory of Kyoto University.

${ }^{1}$ S.-T. Lo and C.-L. Chen, IEEE Trans. Electron Devices 49, 762 (2002).

${ }^{2}$ B. G. Cho, H. S. Tae, S. I. Chien, S. H. Lee, and J. Y. Kim, SID '02 Digest (Soc. Information Display, Playa del Rey, 2002), p. 440.

${ }^{3}$ J. D. Yi, J. K. Han, K. H. Bu, S. J. Moon, M. S. Kim, W. J. Kim, J. T. Park, H. S. Jang, S. K. Lee, Y. H. Kwon, and J. D. Kim, SID '02 Digest (Soc. Information Display, Playa del Rey, 2002), p. 428.

${ }^{4}$ H. J. Seo, H. Kim, D. C. Jeong, S. H. Jang, H. S. Tae, S. I. Chien, and K. W. Whang, Proceedings of Ninth International Display Workshop (IDW'02), Hiroshima (Soc. Information Display, Tokyo, 2002), p. 813.

${ }^{5}$ K. Yamamoto, H. Kajiyama, K. Suzuki, S. Ho, and Y. Kawanami, SID'02 Digest (Soc. Information Display, Playa del Rey, 2002), p. 856.

${ }^{6}$ K. Tachibana, N. Kosugi, and T. Sakai, Appl. Phys. Lett. 65, 935 (1994).

${ }^{7}$ K. Tachibana, S. Feng, and T. Sakai, J. Appl. Phys. 88, 4967 (2000).

${ }^{8}$ K. Mizokami, K. Tachibana, N. Kosugi, T. Sakai and Y. Wakabayashi, Proceedings of Eighth International Display Workshop (IDW'01), Nagoya (Soc. Information Display, Tokyo, 2001), p. 1755.

${ }^{9}$ K. Tachibana, K. Mizokami, N. Kosugi, and T. Sakai, IEEE Trans. Plasma Sci. 31, 68 (2003)

${ }^{10}$ R. Wendt and H. Lange, J. Phys. D 31, 3368 (1998).

${ }^{11}$ E. H. Choi, J. C. Ahn, M. W. Moon, Y. Jung, M. C. Choi, Y. Seo, G. S. Cho, H. S. Uhm, K. Tachibana, K. W. Whang, and M. Kristiansen, Appl. Phys. Lett. 81, 3341 (2002).

${ }^{12}$ W. G. Lee, M. Shao, J. R. Gottschalk, M. Brown, and A. D. Compann, J. Appl. Phys. 92, 682 (2002).

${ }^{13}$ J. C. Ahn, T. Y. Kim, J. J. Ko, Y. Seo, G. S. Cho, and E. H. Choi, J. Appl. Phys. 87, 8045 (2000).

${ }^{14}$ J. C. Ahn, S. B. Kim, T. S. Cho, M. C. Choi, D. G. Joh, M. W. Moon, Y. H. Seo, S. O. Kang, G. S. Cho, E. H. Cho, and H. S. Uhm, Jpn. J. Appl. Phys. 41, 860 (2002).

${ }^{15}$ G. S. Cho, E. H. Choi, J. G. Kim, Y. G. Kim, J. J. Ko, D. I. Kim, C. W. Lee, Y. H. Seo, and H. S. Uhm, Jpn. J. Appl. Phys. 38, L830 (1999). 